\title{
Hydrophilicity Enhancement of Metal Oxide Nanoparticles Incorporated Polysulfone Ultrafiltration Membrane
}

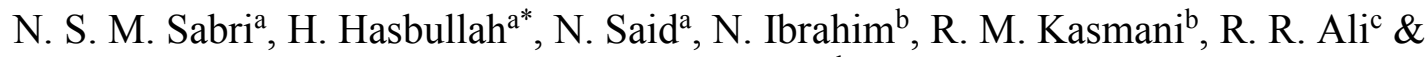 \\ S. A. Rahman ${ }^{\text {d }}$ \\ aAdvanced Membrane Technology Research Centre (AMTEC), Universiti Teknologi \\ Malaysia, 81310 UTM Johor Bahru, Johor, Malaysia \\ ${ }^{b}$ Faculty of Chemical and Energy Engineering, Universiti Teknologi Malaysia, 81310 \\ UTM Johor Bahru, Johor, Malaysia \\ ${ }^{\mathrm{c}}$ Malaysia-Japan International Institute of Technology, Universiti Teknologi Malaysia \\ Kuala Lumpur, Jalan Sultan Yahya Petra, 54100 Kuala Lumpur, Wilayah Persekutuan \\ Kuala Lumpur, Malaysia \\ ${ }^{\mathrm{d}}$ Faculty of Chemical \& Natural Resources Engineering, Universiti Malaysia Pahang, \\ Lebuhraya Tun Razak, Kuantan, Malaysia
}

\begin{abstract}
Hydrophilicity property of membrane is a crucial feature in preventing fouling by most organic components including proteins. In this work, two different metal oxide nanoparticles were selected and their effects on hydrophilicity of polysulfone (PSf) flat sheet membrane for ultrafiltration were investigated. Addition of copper oxide $(\mathrm{CuO})$ and iron oxide $\left(\mathrm{Fe}_{2} \mathrm{O}_{3}\right)$ of $0.25 \mathrm{wt} \%$ concentration in N-methyl-2-pyrrolidone (NMP) were also compared to a neat PSf membrane. The membranes were prepared via dry-wet phase inversion technique with 18 wt $\%$ of PSf with $5 \mathrm{wt} \%$ polyvinylpyrrolidone (PVP). The physical and chemical properties of the prepared membranes were observed by contact angle measurements, porosity, average pore size and scanning electron microscope (SEM). The membranes permeation performance was also examined in term of pure water flux (PWF) and protein rejection by using bovine serum albumin (BSA) solution. Contact angle value of $\mathrm{CuO} / \mathrm{PSf}$ obtained was $67.1^{\circ}$ that was lower than the neat PSf membrane of $87.9^{\circ}$ whereas $68.1^{\circ}$ for $\mathrm{Fe}_{2} \mathrm{O}_{3} / \mathrm{PSf}$ indicating that metal oxides addition did enhance the membrane hydrophilicity with $\mathrm{CuO}$ was slightly better than $\mathrm{Fe}_{2} \mathrm{O}_{3}$. The reduction in contact angle ensured that the pure water flux through the membrane with metal oxide additive would improve as well. For $\mathrm{CuO}$, the PWF increased to $159.3 \mathrm{Lm}^{-}$ ${ }^{2} \mathrm{hr}^{-1}$ from $81.3 \mathrm{Lm}^{-2} \mathrm{hr}^{-1}$ of neat PSf, while $\mathrm{Fe}_{2} \mathrm{O}_{3}$ showed the PWF at $93.4 \mathrm{Lm}^{-2} \mathrm{hr}^{-1}$. Morphological analyses displayed asymmetric membranes with narrow finger-like structure were formed in this study. A well-formed dense top layer indicated that the membrane would possess good BSA rejection property with $92 \%$ of rejection achieved by $\mathrm{CuO} / \mathrm{PSf}$ membrane. The incorporation of nanoparticles with the membrane is proven to be an effective mean to increase the membrane hydrophilicity with improved water flux and BSA rejection.
\end{abstract}

Keywords: Polysulfone, ultrafiltration, copper oxide, iron oxide, hydrophilicity, BSA

\subsection{INTRODUCTION}

In wastewater treatment, membrane technology is high in demand and extensively utilized by industries due to several advantages that are very selective in separation, low space requirement, less energy consumption and higher water quality product that can reduce the environmental impact by effluents [1]. Ultrafiltration (UF) membrane has been widely used in purifying the solution containing high molecular-weight materials [2]. The 
surface pore sizes in the range of 1 to $100 \mathrm{~nm}$ are the main element for UF membranes during the filtration process since it can separate proteins and organic particles from wastewater. Hydrophobic characteristic of proteins is the major influence to cause membrane fouling. Hydrophilicity property is the surface wettability nature of which the tendency of membrane surface to become wet or absorb water better than other materials. Membrane with hydrophilic surface is able to allow the passage of water through the membrane and repels the hydrophobic particle adsorption by repulsive hydration force [3]. Therefore, membrane hydrophilicity and porous structure are two major concerns in UF membrane since these characteristics take important roles in membrane separation.

Polysulfone (PSf) is a good polymer material and widely chosen in UF membrane fabrication due to its properties. Among the advantages of this polymer are excellent film formation and possessing a high degree of chemical, mechanical and thermal stability [4]. However, PSf has its own disadvantages such as hydrophobic in nature that lead to the declination of flux. In order to overcome this shortcoming, previous researchers investigated the blending of hydrophilic additive into polymeric matrix membrane. It is considered as attractive and simple method to modify the membrane without changing the main polymer structure [5]. Usually, hydrophilic polymers and nanoparticles were used as additives to improve PSf membrane hydrophilicity. In polymeric membrane, additive plays various roles including as a pore former, increasing dope solution viscosity and speed up the phase inversion process.

Polyvinylpyrrolidone (PVP) is frequently used in fabricating porous membrane. Previous studies had found that the $18 \mathrm{wt} \%$ of PSf with the addition of $4 \mathrm{wt} \%$ PVP resulted in good membrane permeability [6]. Suppression of macrovoids can be seen when adding a high amount of PVP [7]. This is due to the increasing of polymer solution viscosity that delays the demixing of the polymer solution.

Recently, advancement in nanotechnology has been used in various applications for example in membrane technology. Embedding the nanoparticles (NPs) helps enhancing membranes performance. Several studies were conducted to develop membrane with better separation by NPs addition. The addition of NPs in casting solution is known to be able to reduce the membrane hydrophobicity. NPs with diameter of less than $100 \mathrm{~nm}$ contribute to high surface area per volume. It is reported that addition of AgNP in PSf showed high membrane permeability and separation performance but started to decline when the amount of NPs in the dope was increased further $(>0.25 \mathrm{AgNP})$ [8]. Previous researchers studied the addition of some metal oxide nanoparticles such as $\mathrm{ZnO}, \mathrm{TiO}_{2}$ and $\mathrm{Al}_{2} \mathrm{O}_{3}$ in polymeric membrane. It is reported that high degree of hydrophilicity for PSf membrane when blending with $2 \mathrm{wt} \% \mathrm{TiO}_{2}$ [9]. It was also reported $\mathrm{ZnO}$ addition to polyethersulfone membranes had improved the membrane permeability and fouling resistance [10].

Thus, the main aim of this study was to compare incorporation of potential metal oxide nanoparticle $\left(\mathrm{CuO}\right.$ and $\left.\mathrm{Fe}_{2} \mathrm{O}_{3}\right)$ in PSf membrane. In this work, N-methyl-2-pyrrolidone (NMP) and PVP were used as a solvent and pore former agent, respectively, in membrane fabrication. Membrane hydrophilicity was evaluated by using contact angle measurement and 
membrane morphology using scanning electron microscopy (SEM). The membrane performance was analyzed in terms of water permeation and protein rejection.

\subsection{METHODS}

\subsection{Materials}

All polymers and chemical products obtained were analytical grade and used without further purification. Polysulfone (Udel-P1700) was supplied from Solvay Advanced Polymer as pallets, PVP-K15 by Fluka and NMP (99.5\%, molecular weight = $99.13 \mathrm{~g} / \mathrm{mol}$ ) by QRëC. $\mathrm{CuO}$ size of $<50 \mathrm{~nm}$ (Sigma Aldrich) and $\mathrm{Fe}_{2} \mathrm{O}_{3}$ size of $20 \mathrm{~nm}$ (NovaScientific) was used as metal oxide nanoparticles in dope formulation. Bovine serum albumin of $>98 \%$ purity purchased from Sigma Aldrich was used in protein rejection test. Glycerol (molecular weight $=92.1 \mathrm{~g} / \mathrm{mol}$ ) was obtained from Merck.

\subsection{Preparation of Neat PSF, $\mathrm{CuO} / \mathrm{PSf}$ and $\mathrm{Fe}_{2} \mathrm{O}_{3} / \mathrm{PSf}$ Flat Sheet Membranes}

PSf pallets were dried first in the oven at $50^{\circ} \mathrm{C}$ overnight to remove moisture before preparing the dope. For neat PSf, $5 \mathrm{wt} \%$ PVP were first completely dissolved and stirred by a magnetic stirrer in NMP solvent. After $2 \mathrm{~h}, 18$ $\mathrm{wt} \%$ of PSf was added slowly to the solution at $50^{\circ} \mathrm{C}$ and left for $24 \mathrm{~h}$ while in stir.

As for dope solution containing nanoparticle $\left(\mathrm{CuO}\right.$ or $\left.\mathrm{Fe}_{2} \mathrm{O}_{3}\right), 0.25 \mathrm{wt} \%$ nanoparticle was dispersed first in NMP using sonicator for $1 \mathrm{~h}$ followed by addition of PVP and PSf as previously described.

Table 1 Formulation of membranes

\begin{tabular}{cccccc}
\hline Membrane & $\begin{array}{c}\text { PSf } \\
(\mathbf{w t} \%)\end{array}$ & $\begin{array}{c}\text { PVP } \\
(\mathbf{w t} \%)\end{array}$ & $\begin{array}{c}\mathbf{C u O} \mathbf{\% P s} \\
(\mathbf{w t} \%)\end{array}$ & $\begin{array}{c}\mathbf{F e}_{2} \mathbf{O}_{3} \mathbf{N P s} \\
(\mathbf{w t} \%)\end{array}$ & $\begin{array}{c}\text { NMP } \\
(\mathbf{w t} \%)\end{array}$ \\
\hline MN & 18 & 5 & - & - & 77.00 \\
MC & 18 & 5 & 0.25 & - & 76.75 \\
MF & 18 & 5 & - & 0.25 & 76.75 \\
\hline
\end{tabular}
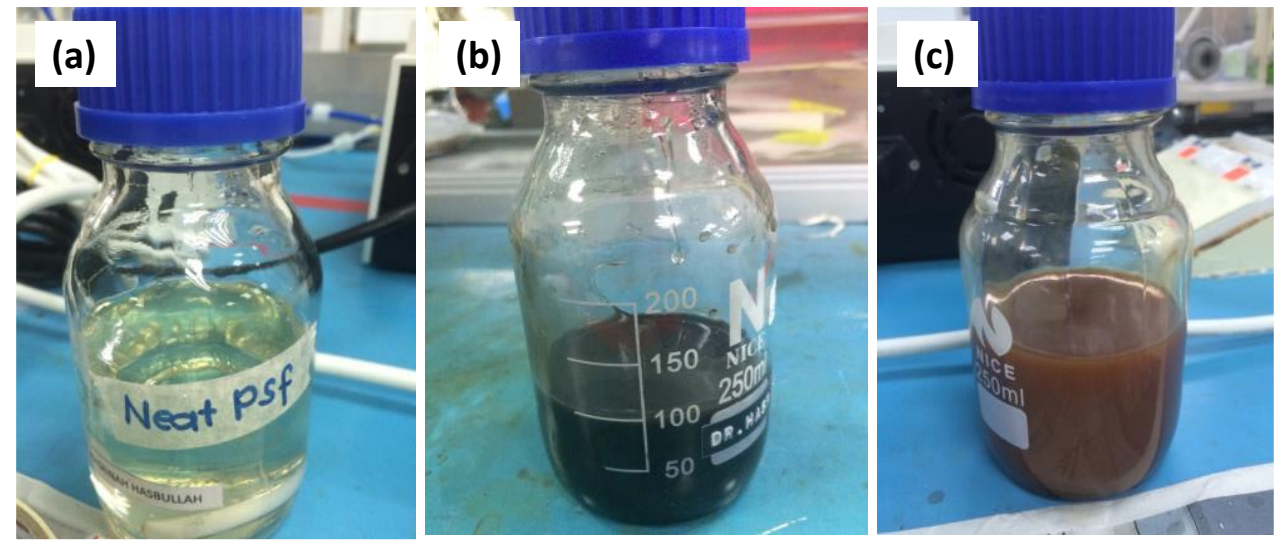

Figure 1 Polysulfone dope solution contains (a) neat polymer, (b) $\mathrm{CuO}$ and (c) $\mathrm{Fe}_{2} \mathrm{O}_{3}$ 
Table 1 shows the prepared dope composition and Figure 1 depicts the polymer solution. All flat sheet membranes were prepared by phase inversion method to form asymmetric structure. Ample amount of dope solution was cast on a clean glass plate and then left it for 10 seconds for solvent evaporation at room temperature before immersed the glass plate into the water bath. The formed membranes were then treated for 4 days to remove residual solvent and to maintain the membrane shelf-life. The post-treatment commenced by keeping the membrane in water for 48 hours before immersing it in $10 \%$ glycerol solution for 1 day and drying the membrane for $24 \mathrm{~h}$. The dried membrane was kept in a sealed bag prior to further actions.

\subsection{Contact Angle Measurement}

The hydrophilic or hydrophobic behaviour of prepared membrane was analyzed using contact angle. Contact angle measurement was carried out by using goniometer (Krüss Gambult, Germany) with $0.5 \mu \mathrm{L}$ of water were dropped on the surface of the membrane using a syringe. The angles were verified by the software and were performed at eight different locations for each sample to reduce the experimental error. Then, the measurement was averagely reported.

\subsection{Evaluation of Membrane Porosity and Average Pore Size}

Membrane overall porosity, $\varepsilon$ was determined by dry-weight methor order to measure the memt porosity, the membrane sample with certain dimension was dipped in water for $1 \mathrm{~h}$. Then, the membrane surface was dried by filter paper and immediately weighed. The porosity of membrane is defined by Eq (1):

$$
\varepsilon=\frac{\mathrm{w}_{1}-w_{2}}{\mathrm{~V} \rho \mathrm{w}}
$$

where $\varepsilon$ is the porosity of the membrane (\%), $\mathrm{w}_{1}$ is the mass of the wet membrane, $\mathrm{w}_{2}$ is the mass of the dry membrane, $\mathrm{V}$ is the volume of the membrane and $\rho \mathrm{w}$ is the density of water $(1.0 \mathrm{~g} / \mathrm{cm} 3)$. The average pore radius, $r(\mathrm{~m})$ was calculated using by the filtration velocity method GueroutElford-Ferry equation (2):

$$
r=\sqrt{\frac{(2.9-1.75 \varepsilon) \times 8 \eta l Q}{\varepsilon \times A \times \Delta P}}
$$

where $\eta$ is the water viscosity at $25^{\circ} \mathrm{C}$, $l$ is the membrane thickness $(\mathrm{m}), \mathrm{Q}$ is the volume of the permeate water per unit time $\left(\mathrm{m}^{3} / \mathrm{s}\right), A$ is the effective area of membrane $\left(\mathrm{m}^{2}\right)$ and $\Delta \mathrm{P}$ is the operational pressure $(\mathrm{Pa})$. Pore size (diameter) of membrane was determined by multiplying $\mathrm{r}$ by 2 .

\subsection{Scanning Electron Microscopy (SEM) Analysis}

The cross-section morphology of the membrane was observed using SEM (HITACHI TableTop TM3000). All the samples were immersed into liquid nitrogen and fractured to obtain clear and smooth cross section. The fractured membranes were stick onto a metal plate at lateral side and then the samples were sputter-coated with platinum/palladium before being analyzed. The images of cross-sections for all membranes were captured.

\subsection{Pure Water Flux Study}

The pure water flux (PWF) were measured by testing the membrane using a dead-end ultrafiltration system that passing through effective surface area $\left(14.62 \mathrm{~cm}^{-2}\right)$ as shown in Figure 2 
at a trans-membrane pressure of 0.98 bar using the following Equation (3):

$$
J=\frac{\mathrm{V}}{\mathrm{A} \times \Delta \mathrm{t}}
$$

where $\mathrm{J}$ represents the PWF $\left(\mathrm{Lm}^{-2} h^{-1}\right)$, $\mathrm{V}$ is the volume of permeate $(\mathrm{L}), \mathrm{A}$ is the effective surface area $\left(\mathrm{m}^{2}\right)$ and $\Delta \mathrm{t}$ is the permeation time $(\mathrm{h})$.

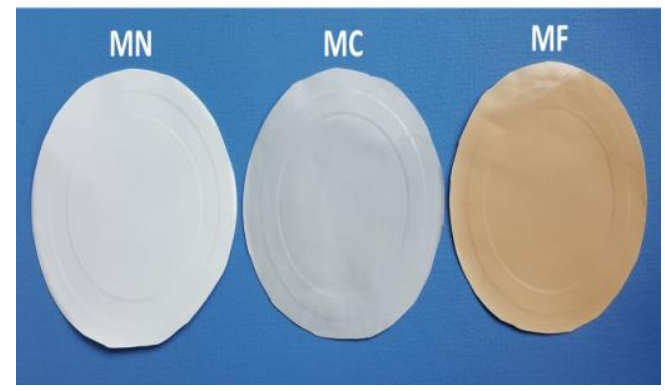

Figure 2 Prepared membrane with specific effective surface area for water flux analysis

\subsection{BSA Rejection Measurement}

For protein rejection test, all membranes were tested at constant transmembrane pressure of 1 bar using $500 \mathrm{mg} / \mathrm{L} \mathrm{BSA}$ solution as a feeding solution. The BSA solution was prepared by dissolving $0.5 \mathrm{mg}$ of BSA powder in $1 \mathrm{~L}$ of distilled water. The percentage of BSA rejection $(\% \mathrm{R})$ was calculated using Equation (4):

$$
\% R=\left(1-\frac{C_{P}}{C_{F}}\right) \times 100
$$

where $\mathrm{C}_{\mathrm{P}}$ and $\mathrm{C}_{\mathrm{F}}$ are the concentrations of BSA in the permeate and feed. The concentration of BSA was measured using UV-Vis Spectrophotometer (DR $5,000)$ at a wavelength of $280 \mathrm{~nm}$.

\subsection{RESULTS AND DISCUSSION}

\subsection{Membrane Hydrophilicity}

The membrane hydrophilicity was determined by measuring the angle between water droplet and flat membrane surface. Hydrophilicity was indicated by the declination of contact angle value.

Table 2 shows the measurements of contact angle for the prepared membranes. The contact angle decreased from $87.9^{\circ}$ for neat membrane $(\mathrm{MN})$, to $68.0^{\circ}$ for $\mathrm{MF}$ and $67.1^{\circ}$ for $\mathrm{MC}$.

It is found that the contact angle decreased upon adding metal oxide nanoparticle in the polymer solutions as compared to a neat membrane. This occurrence could be attributed to the presence of nanoparticles that has lowered down the surface tension of neat PSf, hence, water could easily spread and attracted on membrane surfaces [11]. The trend of contact angle in this study is concurring to the study conduct by [12] on incorporation of the NPs in polymeric membranes.

The contact angle values decreased may also contribute by the migration of NPs to the membrane surface during phase inversion in water. The hydrophilic nature of NPs that embedded in polymeric membrane also contributed to making membrane surface more hydrophilic [13], [14]. This is due to the polarity of a hydroxyl group and oxygen element from the surface of metal oxide that can form interaction with water through Van der Waal's force and hydrogen bonding [15]. This feature of metal oxide NPs remarkably influences the water towards membrane.

Compared by the incorporation of difference metal oxide nanoparticle, the contact angle for $\mathrm{MC}$ is slightly more hydrophilic than MF. This is due to the water affinity and higher density 
of electrostatic charge on the surface of copper oxide [12].

Table 2 Contact angle of the membrane

\begin{tabular}{cc}
\hline Membranes & Contact angle (degree) \\
\hline MN & 87.9 \\
MC & 67.1 \\
MF & 68.0 \\
\hline
\end{tabular}

\subsection{Porosity and Average Pore Size of Membranes}

Porosity is an indicator in membrane permeation and morphology. Membrane porosity was investigated from water uptake experiment. The calculated values are illustrated in Figure 3 along with the value of membrane average pore size.
From the figure, the porosities of membranes containing metal oxide NPs increases as compared to neat PSf membranes. During phase inversion, the presence of hydrophilic additives in casting solution enhanced the mass transfer of non-solvent (water) into the membrane for the development of freevolume and porous membrane [15]. The addition of PVP also influenced this morphology as the porosity of $\mathrm{MN}$ was $46.67 \%$. This is because the site of PVP used to deposit has become micropores during the leaching of PVP in phase inversion process [16].

It can be seen from the graph that average pore size radius slightly increase with the incorporation of NPs. High membrane average pore size was expected to increase the water permeation as the water can pass through the membrane easily.

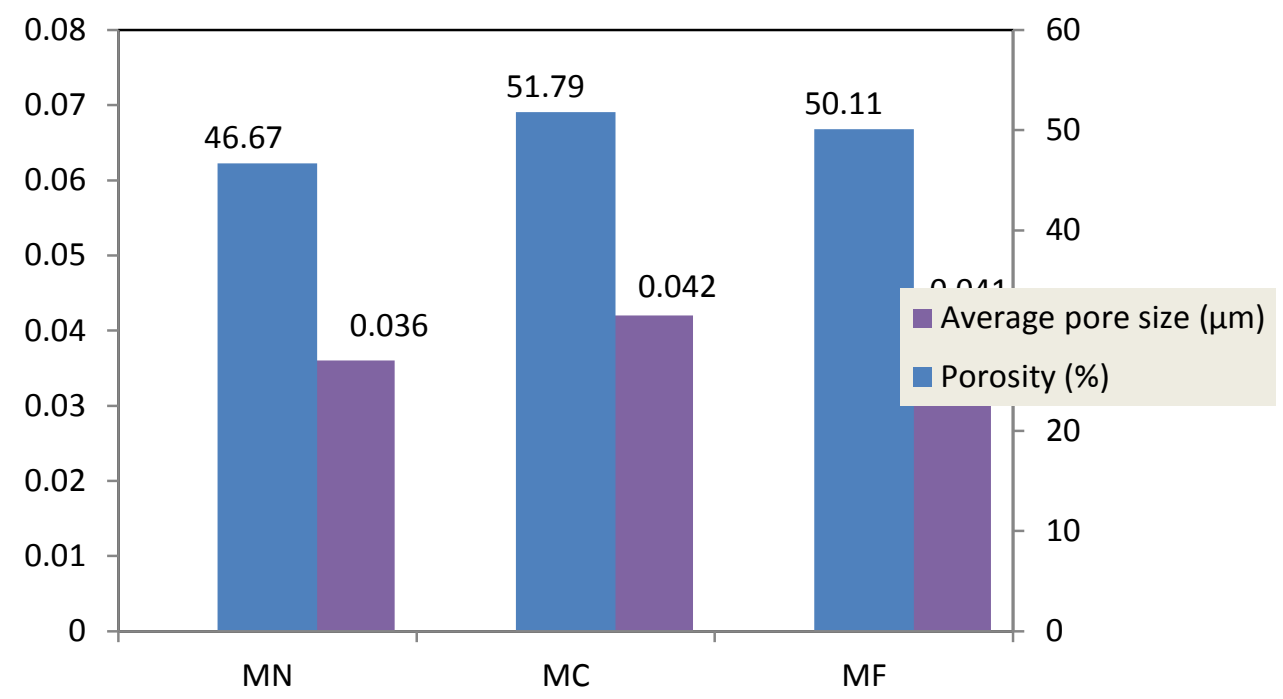

Figure 3 Porosity and average pore size of membranes

\subsection{Scanning Electron Microscopy (SEM) Analysis}

The morphological structures of prepared membranes are presented in Figure 4 using cross-sectional images of SEM. The images showed that all prepared membranes were in the form of asymmetric porous with dense skin layer. From the figure, the sublayer comprised of finger-like structure beneath the top surface as well as macrovoids structure. The formation of this structure is commonly related to the interaction of dope solution and non-solvent (water) during phase 
inversion. Previous research done by [17] give similar result regarding the PSf cross section membrane having dense skin layer and porous sublayer when incorporating with hydrophilic additive.

From Figure 4, MC and MF exhibit the formation of many finger-like structures underneath of the top layer as compared to $\mathrm{MN}$. The presence of longer finger like structure at sublayer helps the transport of the water pass through the membrane compared to short finger-like structure [18]. It can also be observed that MC and MF have narrow finger-like structure.

As compared to $\mathrm{MN}$, the size of macrovoid had slightly reduced when adding metal oxide NPs. This could be due to the hydrophilic effect of NPs and increment of dope viscosity that effect the mass transfer process in coagulation step during casting [19]. The NPs are apparent in Figure 4, which are located within finger like structure in porous sublayer. The toplayer of membranes having a dense skin layer plays an important role as a selective barrier for separation. In this study, the estimated average skin layer thickness for both MF and MC are approximately $0.33 \mu \mathrm{m}$ compared to MN having of $0.28 \mu \mathrm{m}$. This happened since the incorporation of NPs makes a dope solution more viscous, which resulted in delayed demixing during phase inversion process. High dope concentration in the top layer of the membrane was induced during solvent evaporation, causing a thicker membrane skin layer [20].
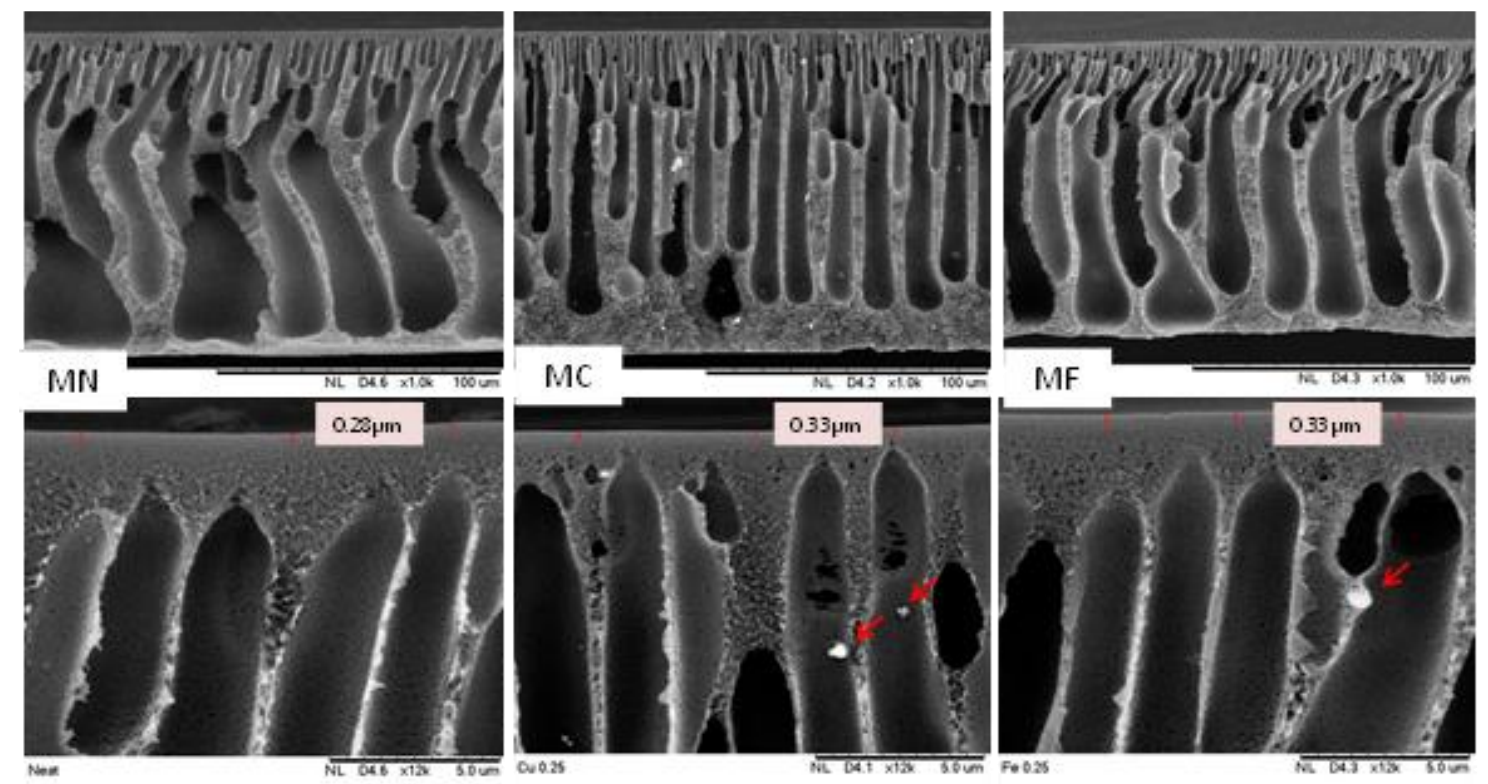

Figure 4 Cross-sectional view of SEM image at $1.0 \mathrm{~K}$ and $12 \mathrm{~K}$ magnification. (Red arrow indicate the metal oxide NPs)

\subsection{Pure Water Flux Analysis}

The results of PWF with respect to different metal oxide NPs incorporated in membranes are presented in Figure 5. The order of water flux was $\mathrm{MN}<\mathrm{MF}<\mathrm{MC}$. The results showed that PWF increased significantly to 159.3
$\mathrm{Lm}^{-2} \mathrm{hr}^{-1}$ for MC from $81.3 \mathrm{Lm}^{-2} \mathrm{hr}^{-1}$ of MN. Pure water flux of MF also showed increment. As indicated by the contact angle values, the MF with higher contact angle than $\mathrm{MC}$, has lower PWF.

These results can be explained based on the contact angle results. The 
addition of NPs induced the membrane surface to be hydrophilic and expected to improve water permeation rate by attracting water molecules inside the membrane matrix and promoted water to pass through the membranes.

Membrane porosity could also contribute to this flux enhancement [19]. In this study, the addition of NPs and PVP resulted in the membrane to have porous structure. The creation of this void in the prepared membrane helped the water transport crossing through the membrane.

\subsection{Protein Rejection Study}

Protein separation property was tested with the BSA solution through the prepared membrane. In this study, BSA solution was used as a model for protein. From Figure 5, MC shows better BSA rejection performance with $92 \%$ and rejection percentage of MF $81 \%$ compared to $59 \%$ rejection by MN. As shown by SEM images, the formation of skin layer in the membrane structure aided the rejection performance as it acted as a selective layer that retained the movement of BSA molecules.

Membrane hydrophilicity also contributed to the BSA filtration study. Membrane with improved hydrophilicity attracts more water molecules to the membrane surface and leaving the hydrophobic nature of BSA behind. Thus, a high protein removal can be achieved by incorporating metal oxide nanoparticles.

\subsection{CONCLUSIONS}

Modification of PSf membranes was conducted by incorporating metal oxide nanoparticle as additives. Incorporation of metal oxide NPs in PSf membrane was successfully prepared by phase inversion process. The experimental results show that these NPs have an important influence on the hydrophilicity PSf membrane and the performances. It was found in this study that addition of $\mathrm{CuO}$ in PSf membrane improved the membrane hydrophilicity with high water flux and better BSA rejection than $\mathrm{Fe}_{2} \mathrm{O}_{3}$. The produced membrane morphology had skin layer and longer finger-like structure that assisted further the BSA rejection across the membrane. As a conclusion, addition of metal oxide NPs was proven to enhance the membrane hydrophilicity with $\mathrm{CuO}$ showing slightly better separation performance than $\mathrm{Fe}_{2} \mathrm{O}_{3}$.

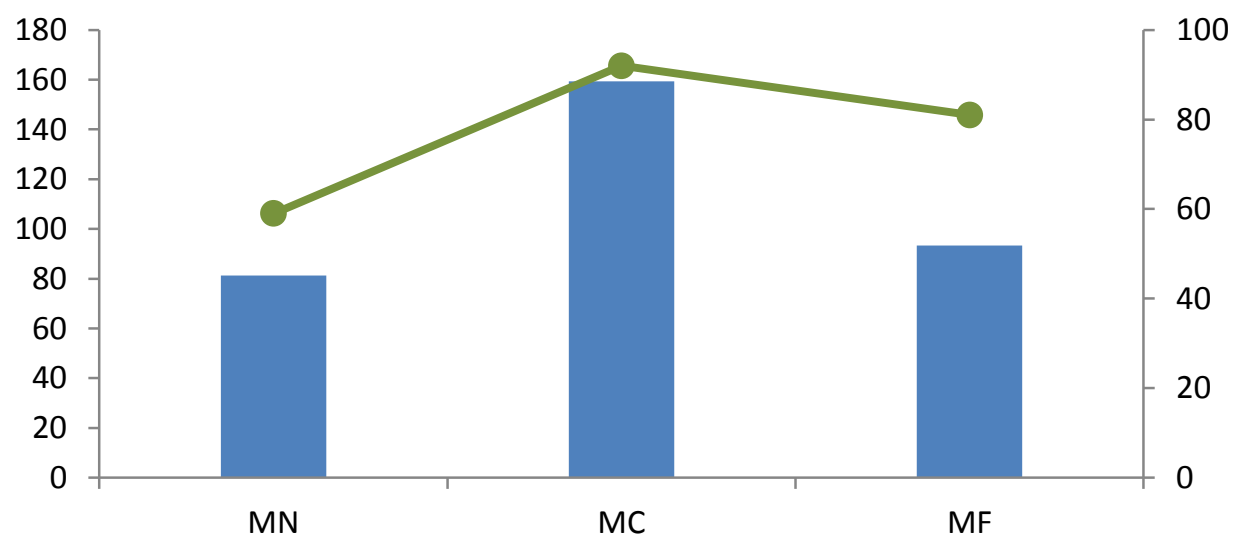

Figure 5 PWF and BSA rejections of the membranes 


\section{ACKNOWLEDGEMENT}

We gratefully acknowledge the financial support from Universiti Teknologi Malaysia and Ministry of Higher Education Malaysia (Grant no: 13H64 and 4J206).

\section{REFERENCES}

[1] S. Shirazi, C. J. Lin, and D. Chen. 2010. Inorganic Fouling of Pressure-driven Membrane Processes-A Critical Review. Desalination. 250(1): 236-248.

[2] N. Ali, H. Sofiah, A. Asmadi, and A. Endut. 2011. Preparation and Characterization of a Polysulfone Ultrafiltration Membrane for Bovine Serum Albumin Separation: Effect of Polymer Concentration. Desalin. Water Treat. 32(1-3): 248-255.

[3] L. Huang, S. Zhao, Z. Wang, J. Wu, J. Wang, and S. Wang. 2016. In Situ Immobilization of Silver Nanoparticles for Improving Permeability, Antifouling and Anti-bacterial Properties of Ultrafiltration Membrane. $J$. Memb. Sci. 499: 269-281.

[4] M. K. Sinha and M. K. Purkait. 2013. Increase in Hydrophilicity of Polysulfone Membrane Using Polyethylene Glycol Methyl Ether. J. Memb. Sci. 437: 7-16.

[5] Z. Xu, S. Ye, F. Zheng, R. Fanghua, G. Congjie, L. Qingbiao, L. Guoqing, Z. Guoliang. 2015. Preparation of $\mathrm{Cu}_{2} \mathrm{O}$ Nanowireblended Polysulfone Ultrafiltration Membrane with Improved Stability and Antimicrobial Activity. J. Nanoparticle Res. 17: 409: 10: 1-9.

[6] A. Urkiaga, D. Iturbe, and J. Etxebarria. 2015. Effect of Different Additives on the Fabrication of Hydrophilic
Polysulfone Ultrafiltration Membranes. Desalin. Water Treat. 56(13): 3415-3426.

[7] C. Mbareck and Q. T. Nguyen, 2014. Study of Polysulfone and Polyacrylic Acid (PSF/PAA) Membranes Morphology by Kinetic Method and Scanning Electronic Microscopy. J Membra Sci Technol. 5(1): 1-7.

[8] D. Y. Koseoglu-Imer, B. Kose, M. Altinbas, and I. Koyuncu. 2013. The Production of Polysulfone (PS) Membrane with Silver Nanoparticles (AgNP): Physical Properties, Filtration Performances, and Biofouling Resistances of Membranes. $J$. Memb. Sci. 428(1-3): 620-628.

[9] N. A. A. Hamid, A. F. Ismail, T. Matsuura, A. W. Zularisam, W. J. Lau, E. Yuliwati, M. S. Abdullah. 2011. Morphological and Separation Performance Study of Polysulfone/Titanium Dioxide $\left(\mathrm{PSF} / \mathrm{TiO}_{2}\right) \quad$ Ultrafiltration Membranes for Humic Acid Removal. Desalination. 273(1): 85-92.

[10] T. D. Dipheko, K. P. Matabola, K. Kotlhao, R. M. Moutloali, and M. Klink. 2017. Fabrication and Assessment of $\mathrm{ZnO}$ Modified Polyethersulfone Membranes for Fouling Reduction of Bovine Serum Albumin. Int. J. Polym. Sci. 8.

[11]H. Basri, A. F. Ismail, and M. Aziz. 2011. Polyethersulfone (PES)-silver Composite UF Membrane: Effect of Silver Loading and PVP Molecular Weight on Membrane Morphology and Antibacterial Activity. Desalination. 273(1): 72-80.

[12]N. Akar, B. Asar, N. Dizge, and I. Koyuncu. 2013. Investigation of Characterization and Biofouling Properties of PES membrane Containing Selenium and Copper 
Nanoparticles. J. Memb. Sci. 437: 216-226.

[13]M. Homayoonfal, M. Reza, M. Shariaty-niassar, and A. Akbari. 2014. A Comparison Between Blending and Surface Deposition Methods for the Preparation of Iron Oxide/Polysulfone Nanocomposite Membranes. Desalination. 354: 125-142.

[14]A. S. Al-Hobaib, K. M. AlSheetan, M. R. Shaik, N. M. AlAndis, and M. S. Al-Suhybani. 2015. Characterization and Evaluation of Reverse Osmosis Membranes Modified with $\mathrm{Ag}_{2} \mathrm{O}$ Nanoparticles to Improve Performance. Nanoscale Res. Lett. 10(1): 379.

[15]A. Sotto, J. Kim, J. M. Arsuaga, G. del Rosario, A. Martínez, D. Nam, P. Luis, B. Van der Bruggen. 2014. Binary Metal Oxides for Composite Ultrafiltration Membranes. J. Mater. Chem. A. 2(19): 7054-7064.

[16] M. O. Mavukkandy, M. R. Bilad, A. Giwa, S. W. Hasan, and H. A. Arafat 2016. Leaching of PVP from PVDF/PVP Blend Membranes: Impacts on
Membrane structure and Fouling in Membrane Bioreactors. $J$. Mater. Sci. 51(9): 4328-4341.

[17] S. R. Panda and S. De. 2013. Role of Polyethylene Glycol with Different Solvents for Tailor-made Polysulfone Membranes. J. Polym. Res. 20(7): 16.

[18]M. Z. Yunos, Z. Harun, H. Basri, A. F. Ismail, and D. Wang. 2012. Effects of Water as Non-Solvent Additive on Performance of Polysulfone Ultrafiltration Membrane. Adv. Mater. Res. 488489: 46-50.

[19]J. Alam, L. A. Dass, M. Ghasemi, and M. Alhoshan. 2013. Synthesis and Optimization of $\mathrm{PES}-\mathrm{Fe}_{3} \mathrm{O}_{4}$ Mixed Matrix Nanocomposite Membrane : Application Studies in Water Purification. Polym. Compos. 34(11): 1-8.

[20]P. T. P. Aryanti, S. R. Joscarita, A. K. Wardani, S. Subagjo, D. Ariono, and I. G. Wenten. 2015. The Influence of PEG400 and Acetone on Polysulfone Membrane Morphology and Fouling Behaviour. J. Eng. Technol. Sci. 48(2): 173-182. 